\title{
THE SMALLEST SALABLE PATENT-PRACTICING UNIT (“SSPPU”) EXPERIMENT, GENERAL PURPOSE TECHNOLOGIES AND THE COASE THEOREM
}

\author{
Nicolas Petit ${ }^{*}$
}

\section{INTRODUCTION}

1.01 economics teach that markets work efficiently when prices reflect externalities. The price system rewards producers' activities that increase the welfare of other economic agents - a positive externality. This attracts welfare-enhancing production to markets. Conversely, the price system penalizes producers' activities that decrease the welfare of other economic agents - a negative externality. This deters investment in socially harmful activities. Importantly, the Coase theorem adds that the price system will only properly reflect externalities if property rights are well delineated and there are no transactions costs (Coase, 1960).

In the last year, some Standard-Setting Organizations ("SSOs") active in wireless communications have - under the lenient eye of antitrust agencies - experimented new technology pricing principles which upset this basic economic wisdom. One of those changes is the "SSPPU" experiment. Under SSPPU pricing, the licensing rates paid (read prices) to owners of standard essential patents ("SEPs") for the use of their technology shall reflect the "value that the functionality of the claimed invention or inventive feature ... contributes to the value of the relevant functionality of the smallest saleable Compliant Implementation that practices the Essential Patent Claim”. In plain English, prices charged for technology should reflect the value added to the smallest component embodying the patented invention.

SSPPU wants to prevent upstream technology developers to claim all or a share of the value added to the end product sold by original equipment manufacturers on downstream markets. This practice, which is sometimes referred to as the Entire Market Value Rule ("EMVR"), has received wide media coverage in the smartphone industry, where royalties are conventionally calculated as a percentage of final handset prices so as to reflect the value added to end user by the patented component (say, $5 \%$

\footnotetext{
* Professor, University of Liege (ULg) School of Law and Liege Competition and Innovation Institute (“LCII”). Nicolas.petit@ulg.ac.be.
} 
of the retail price of an iPhone). Some authors have claimed that this creates a problem of "royalty stacking" (Lemley and Shapiro, 2007), given the thousands SEPs included in a standard, and the thousand standards implemented in a smartphone. An empirical study - whose findings have been criticized - has found that the royalty stack represents a burden of $\$ 120$ on a hypothetical $\$ 400$ smartphone. At the end of the line, royalty stacking is said to decrease innovation to the detriment of society at large.

As all intuitive ideas, SSPPU pricing has some appeal. But on second thoughts, its implications are so likely counterproductive that it should remain what it is, an experiment. Basic economic theory, and a fictional example, help demonstrate this.

\section{A TAle of the Aircraft Industry}

Take firm A and B. A is a technology firm that develops wireless communications technology. B is a vertically integrated manufacturer of commercial aircrafts. A holds a portfolio patents which have been declared essential to an ITU standard entitled Wireless Avionics IntraCommunications ("WAIC"). ${ }^{1}$ WAIC sets specifications for wireless communications between two or more points on a single aircraft. WAIC is primarily about safety-related applications: release of oxygen masks, trigger of oxygen flow, emergency lighting, cabin pressure, etc.

Under WAIC, aircrafts manufacturers can literally cut costs. Few people know that a standard Airbus A-380 embarks approximately 5700 kilograms (kgs) of electrical wires. With wireless technology, approximately $30 \%$ of the entire aircraft electrical wire (ie 1710 kilograms) can be stripped. ${ }^{2}$ This, in turn, represents massive economies in fuel consumption (and lower carbon dioxide (CO2) emissions). Given that fuel consumption is "probably the single most important item in airlines' operating costs", WAIC is likely to drive up the demand of airlines customers' on the market for commercial aircrafts. ${ }^{3}$

Let us attempt to calculate a crude empirical estimate of those costs savings. American Airlines considers that a reduction of the mass of each

\footnotetext{
${ }^{1}$ See http://waic.avsi.aero/

2 Notably with the elimination of double or triple wiring redundancies. See https://www.itu.int/net/ITU-R/study-groups/docs/workshop-wp5abc-wrc15/WP5ABCWRC15-P2-5.pdf

${ }^{3}$ M. Givoni and P. Rietveld, “Airline's choice of aircraft size - Explanations and Implications", Transportation Research Part A 43 (2009) 500-510.
} 
aircraft by $14,5 \mathrm{kgs}$ yields a yearly fuel economy of $\$ 1.2$ million across its entire fleet. ${ }^{4}$ This represents a yearly saving of $\$ 83,000$ per kg eliminated on all aircrafts. Let us now assume that American Airlines decides to replace its entire fleet of 939 aircrafts with WAIC compliant ones. With those aircrafts, it would make a yearly fuel economy of $\$ 141,9$ million $(\$ 83,000 * 1710)$ on the entire fleet, and an average fuel economy per aircraft of $\$ 151,000$ (\$141,9 million/939). If we assume that an aircraft has a 20 years lifespan, this amounts to total benefits of $\$ 3,02$ million per WAIC compliant aircraft.

With this background, let us return to our fictional example. B decides to implement WAIC in next generation aircrafts. B liaises with A to negotiate a license on its SEPs. How should this license be priced under the SSPPU? The SSPPU seems to preclude to take account of the value added to the end product, ie the aircraft. Instead, it forces to focus on the added value to the smallest salable patent-practicing implementation. In this case, the SSPPU is the Radio Frequency ("RF") equipment, ie antennas, transmitters and receivers. ${ }^{6}$ A will thus secure licensing revenue that represents a fraction of the (internal) price of RF equipment. That is essentially plastic, silicon and semi-conductors.

\section{EXTERNALITIES}

From an economic standpoint, the defect of this approach is so obvious that it does not deserve long critique. A is only entitled to appropriate a fraction of the value created by its technology, and has no claim whatsoever over the value added to end users, ie the fuel efficiencies made by airlines. The concept of value added to end user can also be illustrated with a consumer goods example, by contrasting an iPhone versus an iPod. Both use similar components, but one implements patented connectivity technology, not the other. ${ }^{7}$ And the value added to end user changes dramatically.

To be sure, under the SSPPU regime, A remains in theory free to

\footnotetext{
${ }^{4}$ http://www.wired.com/2012/09/how-can-airlines-reduce-fuel-costs/

${ }_{5}^{5}$ https://en.wikipedia.org/wiki/American_Airlines fleet

${ }^{6}$ In reality, the SSPPU may be even lead to focus on more granular implementations, like for instance, chipsets which ensure frequency sharing within RF transmitters. Frequency sharing techniques enable share spectrum with each other and potentially other users. See https://www.itu.int/dms_pub/itu-r/opb/rep/R-REP-M.2197-2010-PDF-E.pdf

${ }^{7}$ Or taking for instance a Samsung Galaxy tablet, one with WiFi and the other with 3G, LTE or $4 \mathrm{G}$ connectivity.
} 
claim from $\mathrm{B}$ that the value added to the smallest implementation, ie the $\mathrm{RF}$ equipment, is $\$ 3.02$ million. As was noted by the US DoJ, SSPPU does not prevent to raise the royalty rate $(r)$ in order to reflect that the patented functionality drives demand for the end product". ${ }^{8}$ Is this, however, realistic? If we assume that the value of a RF equipment unit for an aircraft is $\$ 1,000$, then A would have to charge $r=3020 \%$ per RF unit. This would look like plain vanilla monopoly pricing, and B could certainly resist any such demand. Moreover, it may again be objected that SSPPU does not prevent to use the end product as the royalty base $(b)$. In this variant, A could charge $\$ 3,02$ million on the aircraft price. Given that an A380 sells (list price) for $\$ 414,4$ million, then the parties could settle for $r=0,72 \%$. Facially, this rate would stay within the confines of a fair and reasonable price. However, this proposition is again unrealistic. ${ }^{9}$ In the SSPPU world, B can resist demands to use the aircraft price as the appropriate royalty base, because SSPPU imposes to focus licensing talks on the value added to the component, ie the RF equipment. If $\mathrm{A}$ was ever to offer a $0,72 \%$ rate on the end product, B could perfectly challenge this proposed methodology as inapt to reflect the added value of the smallest compliant implementation. In turn, B could offer to discuss the price (and cost) of RF equipment as a more appropriate royalty base. From a practical standpoint, SSPPU thus tends to promote component licensing as the default rule in bilateral negotiations, and to marginalize the industry practice of end-product licensing.

At a more stylized level, because SSPPU ring fences licensing talks around the value of the smallest salable component, it can be deemed to take off the negotiation table the positive production externalities enjoyed by other economic agents. This interference with the price system is unfortunate. Prices that do not reflect positive production externalities send counter-productive signals to investors, and may result in underinvestment.

\footnotetext{
${ }^{8}$ See US DoJ, Business Review Letter, 15-1 Institute of Electrical and Electronics Engineers, Incorporated ("IEEE"), 2 February 2015.

${ }^{9}$ As Geradin and Layne Farrar observe, "From a mathematical perspective, of course, the individual elements of a royalty payment, in isolation, are irrelevant, as one variable can adjust with the other. Whether we apply a $1 \%$ royalty rate to a $\$ 100$ product price or a $10 \%$ royalty rate to a $\$ 10$ value component, the per unit royalty payment will be $\$ 1$ ". However, the authors observe that this mathematical neutrality does not hold in the real world, due to many practical considerations. D. Geradin and A. Layne-Farrar, "Patent Value Apportionment Rules for Complex, Multi-Patent Products", 27 Santa Clara High Tech. L.J. 763 (2010).
} 
This externality problem is not trivial, and certainly acute in relation to "general purpose" technologies ("GPT") - better known from the public as "enabling technologies". ${ }^{10}$ Bresnahan and Tratjenberg define GPTs as technologies that (i) are used as inputs by many downstream sectors; (ii) present inherent potential for technical improvements, and (iii) bring about innovational complementarities (Bresnahan and Tratjenberg, 1995). Textbook examples include the steam engine, semiconductors, computers, the Internet and wireless technologies.

GPTs are quantum leaps that yield countless positive production externalities. Bresnahan and Tratjenberg talk of them as the "engines of growth". ${ }^{11}$ In particular, GPTs yield vertical externalities - between the technology and the applications sector (here, in aircraft manufacturing) and horizontal ones - across sectors (here, across aircraft manufacturers and the aerospace industry, for instance). Bresnahan and Tratjenberg further hint that market institutions (like possibly SSPPU) may, if wrongly designed, prevent the appropriation of those externalities, and hinder the development of GPTs. ${ }^{12}$

\section{TRANSACTION COSTS}

In the world of Coase, parties bargain over a price that reflects externalities, including positive production externalities. To take a wellknown example in the economics literature, if roaming bee hives pollinate neighboring apple crops, then beekeepers can seek compensation from apple farmers through market transactions. ${ }^{13}$ However, a standard condition for the Coase theorem to apply, is that the "market transactions are costless". ${ }^{14}$ Coase later explained that he did not believe that markets

${ }^{10}$ T. Bresnahan and M. Trajtenberg, "General Purpose Technologies: Engines of Growth", Journal of Econometrics, 1995, vol. 65, issue 1, pages 83-108.

${ }^{11}$ Across the world, large public policy programmes have been adopted to promote research in key enabling technologies. See Communication from the Commission, "A European strategy for Key Enabling Technologies - A bridge to growth and jobs", Brussels, 26.6.2012 COM(2012) 341 final.

${ }^{12}$ E. Helpman, General Purpose Technologies and Economic Growth, Cambridge, MA: The MIT Press, 1998.

${ }^{13}$ Cheung showed this empirically, by observing in the Yellow Pages that a market for pollination services existed in rural Washington. S. Cheung, "The Fable of the Bees: An Economic Investigation", 16 J. Law \& Econ. 11 (1973). See also, M. Muth, R. Rucker, W. Thurman and CT. Chuang, "The Fable of the Bees Revisited: Causes and Consequences of the U.S. Honey Program", The Journal of Law \& Economics, Vol. 46, No. 2 (October 2003), pp. 479-516.

${ }^{14} \mathrm{R}$. Coase, supra. 
with 0 transaction costs existed. He nonetheless insisted that the price system worked efficiently when transactions costs are limited.

Interestingly, SSPPU inflates by a non-trivial margin the transaction costs between SEP owners and implementers. The adverse transaction costs effect of SSPPU can be observed at several levels. Firstly, the value of the smallest salable component practicing the patent will often be information privy to the firm that practices the patent. In our example, B is a vertically integrated aircraft manufacturer that internally produces avionics, including RF components. The price of RF components is a transfer price unknown from A. And even if $\mathrm{B}$ were to procure RF components on a market - for instance from subcontractor $\mathrm{C}-\mathrm{A}$ is not party to the $\mathrm{B}-\mathrm{C}$ exchange. The cost incurred by A to figure out the value of the smallest salable compliant implementation under SSPPU pricing is therefore likely to be much higher than reliance on other observable metrics, including end user profits or prices.

This problem explains why, in many patent intensive sectors, such as medical devices and food ingredients, the industry rule is that licensing contracts apportion a share of the end product profits to the patent owner. ${ }^{15}$ And more generally, this also explains the pervasiveness of the $25 \%$ rule of thumb in intellectual property transactions. ${ }^{16}$

Secondly, SSPPU itemizes licensing negotiations. Under SSPPU pricing, the patent owner and the prospective licensee must agree upon the value brought by each patented functionality. This means that each SEP or, to be more accurate, each "Essential Patent Claim" - must receive a price. As if the beekeeper and the farmer had to set a fee for the pollination externality discharged by each individual bee. This again is likely to increase transaction costs in sectors where technology developers hold more than one or a few SEPs (and possibly other IP rights, including

${ }^{15}$ Strictly speaking, SSPPU does not prevent to spell out licensing fees in the form of royalties on end product price. However, it forbids to value the technology as a function of the end product revenue, profits or price.

${ }^{16}$ Which sets that royalty represent one fourth of the profits made by the product that embodies the patented technology. R. Goldscheider, J. Jarosz and C. Mulhern, "Use Of The 25 Per Cent Rule In Valuing IP", Les Nouvelles, December 2002, p.123; R. Razgaitis, "Pricing the Intellectual Property of Early-Stage Technologies: A Primer of Basic Valuation Tools and Considerations", in A. Krattiger et al, Intellectual property management in health and agricultural innovation: a handbook of best practices, Volumes 1 and 22007 pp. 813-860. See also, KPMG International, Profitability and royalty rates across industries: Some preliminary evidence, 2012. 
ordinary patents, trademarks, copyrights, trade secrets, etc.), and where "portfolio licensing" has become conventional practice for pragmatic reasons, ie essentially to avoid costly contract renegotiation when parties' patent positions change over time (which is frequent, in consumer electronics and semiconductors). ${ }^{17}$

Thirdly, SSPPU pricing will generate endless discussions over valuation benchmarks. Let us recall the wording of the SSPPU rule: "value that the functionality of the claimed invention ... contributes to the value of the relevant functionality of the smallest saleable Compliant Implementation that practices the Essential Patent Claim". In our example, the "relevant functionality of the smallest saleable compliant implementation" is the functionality of WAIC compliant RF equipment, and it can be broadly defined as inflight security communications. In turn, the "functionality of the claimed invention" of $\mathrm{A}$ is wireless communications. Thus, the inquiry shall revolve around assessing the added value of wireless technology to inflight security communications. There is not just a single way to deal with this. One approach is to construe the added value as the savings achieved by $\mathrm{B}$, when it transitions from electrical wire to RF equipment for inflight security communications. Those savings essentially consist in costs economies made by the avoidance of electrical wiring, maintenance and replacement. But does this include the savings made by redesigning the factories to take advantage of the novel technology? ${ }^{18}$ And why not instead to gauge the incremental revenue achieved by $\mathrm{B}$, before and after the modification of its production mix? Obviously, all approaches are likely to return distinct SSPPU valuations, and endless methodological disputes amongst the parties' economic experts.

In a 2004 paper, Posner underlined that high transaction costs are inherent in the licensing of intellectual property.19 This is all the more so in GPTs, where uncertainty, asymmetric information and time gaps are of the essence (Bresnahan and Tratjenberg, 1995). With this, the SSPPU principle just adds another brick in the wall of transactional costs faced by parties to licensing negotiations.

${ }^{17}$ P. Grindley \& D. Teece, "Managing Intellectual Capital: Licensing and CrossLicensing in Semiconductors and Electronics", 39 California Management Review, Winter 1997, at 8-10.

${ }^{18} \mathrm{~T}$. Bresnahan and M. Trajtenberg, supra.

19 R. Posner, "Transaction Costs and Antitrust Concerns in the Licensing of Intellectual Property”, (2004) 4 John Marshall Review of Intellectual Property Law, 325. 


\section{CONCLUSION}

On close analyzis, SSPPU pricing is ill-thought. It interferes with the efficient operation of the price system. The proposition that licensing negotiations shall ignore a whole host of positive externalities is likely to reduce investment in socially beneficial activities, including in GPTs which are key drivers of economic growth. Moreover, SSPPU pricing is a nest of transaction costs. The SSPPU rule may thus limit the ability of technology developers and implementers to reach socially efficient bargains.

The bottom-line is that SSOs (and administrative agencies) across the world should not advocate - let alone mandate - SSPPU in SEPs-intensive sectors. This is likely to induce technology developers unwilling to license under SSPPU terms to desert SSOs or, even worse, to reduce their investments in industries where standardization is pervasive. In turn, if patent owners stop contributing their best technology into standardization, then end consumers will not obtain high quality and affordable products. Markets will morph into ecosystems of technological silos, where consumers are being locked-in without a fair price.

Moreover, from a regulatory standpoint, the risk of under-licensing (or deferred licensing) due to increased transaction costs under the SSPPU rule may inescapably prompt compulsory licensing initiatives by administrative agencies. ${ }^{20}$ But as Posner rightly observes in relation to copyright, compulsory licensing certainly removes a transaction costs problem but does not imply zero valuation: "The fee that the licensee under a compulsory license must pay is not meant to defray the licensing costs, in whole or in part, but to compensate the copyright owner for the value of his property (more precisely, the value represented by the copyright). The fee thus is the equivalent of the contract price and is distinct from the transaction costs-the costs of making the contract which are still in this example zero" ${ }^{21}$ Administrative agencies - like the US DoJ - that seem to support the SSPPU experiment shall thus think twice about it, unless they are ready to turn into price regulators and micro manage SEPs licensing fee.

\footnotetext{
${ }^{20}$ A drastic remedy which, to date, has (rightly) remained a "paper tiger". See Van Overwalle and Van Zimmeren, "A Paper Tiger? Compulsory Licenses Regimes for Public Health in Europe" (December 1, 2010. International Review of Intellectual Property and Competition Law (IIC), January 2011, SSRN http://ssrn.com/abstract=1717974, p.37.

${ }^{21} \mathrm{R}$. Posner, supra.
} 